\title{
The Use of Euphemistic Expressions by Arab EFL Learners: Evidence from Al Ain University of Science and Technology
}

\author{
Abdel Rahman Mitib Altakhaineh ${ }^{1} \&$ Hanan Naef Rahrouh ${ }^{2}$ \\ ${ }^{1} \mathrm{PhD}$ candidate in linguistics, Newcastle University, UK \\ ${ }^{2}$ Lecturer of English, Al Ain University of Science and Technology, United Arab Emirates \\ Correspondence: Abdel Rahman Mitib Altakhaineh, School of English Literature, Language and Linguistics, \\ Newcastle University, England, NE1 7RU, UK. Tel: 44-747-313-1314. E-mail: a.r.m.s.altakhaineh@ncl.ac.uk
}

\author{
Received: September 9, 2014 Accepted: October 4, 2014 Online Published: January 27, 2015 \\ doi:10.5539/ijel.v5n1p14 \\ URL: http://dx.doi.org/10.5539/ijel.v5n1p14
}

\begin{abstract}
This study measures the extent to which Arab EFL learners are aware of euphemistic expressions related to two areas, namely, courtesy and physical appearance and whether they are able to recognise them in context. The study also attempts to investigate whether the participants' gender and English proficiency level may play a role in their use of euphemism in their day-to-day lives. For the purposes of the study, we developed a multiple-choice test in which the participants were asked to choose the suitable answer out of four choices. The contextualized sentences used in the test were adapted from the Corpus of Contemporary American English $(C O C A)$ to suit the participants' English proficiency level. Results revealed that Arab EFL learners had little awareness of euphemistic expressions in English. Also, the participants' English proficiency level had little effect on their use of euphemistic expressions. However, the participants' gender played a significant role in their performance on the test. In particular, the female participants were significantly more aware of euphemistic expressions than the males. The study concluded with some pedagogical implications and recommendations for further research.
\end{abstract}

Keywords: euphemism, taboo, offensive expressions, Arab EFL, Arabic

\section{Introduction}

Euphemism is a universal phenomenon that can be defined as an indirect way of substituting a word or a phrase for one considered to be too offensive. Put differently, it is a polite way to replace a word that is considered harsh, unpleasant or inappropriate to say. Euphemism is considered a significant part of every language and people, in general, strive to sound polite and courteous rather than rude.

Recently, the use of euphemistic expressions has started to capture researchers' attention. This may be due to the growing number of euphemistic expressions in different languages and the difficulties EFL learners encounter while learning which euphemism is appropriate in a particular situation. Several studies have focused on the use of euphemistic expressions by EFL learners who have various linguistic and cultural backgrounds, such as Chinese. However, little attention has been given to Arab EFL learners. As a result, this study is a serious attempt to examine the extent to which Arab EFL learners are aware of euphemistic expressions in English. The ultimate goals are to investigate: (1) whether Arab EFL learners' English proficiency levels play a role in their use of euphemistic expressions in English; and (2) whether Arab EFL learners' gender influences their comprehension of euphemism.

\section{Literature Review}

\subsection{Overview}

The English word 'euphemism' is derived from Greek, euphemismos with the prefix eu- which means 'good' and the root phemi which means 'speaking'. Thus, the whole word means "speaking well" (McArthur, 1992:387). When certain words or expressions are too offensive, harsh or carry a high degree of risk for a given social situation, speakers tend to use euphemism. According to Stien (1998), speakers of a language should pay much attention to the destructive power of expressions. It is undoubtedly clear that the feelings and gestures that accompany words could hurt people's feelings and destroy relationships. Euphemism is a tool that helps people communicate in a smooth and effective way. This section summarises a number of studies on the use of 
euphemistic expressions.

\subsection{Euphemism and Culture}

Euphemisms are powerful linguistic tools that "are embedded so deeply in our language that few of us, even those who pride themselves on being plainspoken, ever get through a day without using them" (Rawson, 1981, p. 1). Speakers need euphemism for social and emotional reasons. For instance, the use of euphemism is helpful to discuss many touchy subjects, such as sex, religion and personal appearances. The discussion can be conducted without outraging, hutting or upsetting other people.

In an empirical study, Zizheng (2005) investigates the extent to which the students of two classes at Anhui University have acquired euphemism in English. A test of four parts was designed to judge the student's ability to understand and use euphemism in English. In sum, Zizheng (2005) concludes that euphemism has gained a lot of attention as one of the main subjects of cross-cultural studies since speakers started to realise the significance of euphemism in improving intercultural communications. Zizheng (2005) recommends that English teachers should pay more attention to euphemism and exert more effort to improve students' cross-cultural awareness and communicative competence.

The euphemistic expressions used to refer to the death of a close or an important person in the community differs from one culture to another (Frajzyngier \& Jirsa, 2006, p. 531). An example of this can be detected in many Kwa languages of Ghana in which people say: 'the chief went to the sea' or 'the chief went to the village' instead of 'the chief has died'. The former two expressions are obviously euphemistic. In comparison with English, different euphemistic expressions, such as 'he is not with us', 'he passed away' or 'he met his maker' can be employed in different social classes.

Hai-Long's (2008, pp. 55-56) study supports Frajzyngier and Jirsa's (2006, p. 531) argument. He argues that due to cultural differences, euphemisms in English and Chinese are drastically different. For instance, it has been noticed that English euphemistic expressions are more related to religious taboos compared to Chinese ones. Probably, this resulted from the fact that English-speaking countries are mostly Christian. On the other hand, one of the most used euphemistic expressions in China is related to class distinction as opposed to religion. Also, Hai-Long (ibid) indicates that euphemistic expressions in Chinese focus more on age compared to English-speaking countries. This is maybe due to the fact that in China, elderly people are much respected. Finally, Hai-Long (2008, p. 56) concludes that euphemistic expressions differ based on culture and society. Hence, comprehending euphemism enhances intercultural communication.

What is considered offensive and harmful in one society can be acceptable in another (Fershtman et al., 2011, p. 140). Hence, it can be seen that euphemism is based on cultural values, norms and beliefs. For example, some taboos are associated to dietary restrictions, such as eating kosher food, which are considered a part of the Jewish identity. Kosher restrictions indicate that one cannot eat pork or shellfish, and every food that touches non-kosher food is non-kosher. On the other hand, Hindus are not allowed to eat beef.

\subsection{Euphemism and Gender}

In her study, Lakoff (1975) explores the use of euphemism with reference to women. Specifically, her study sheds light on the roles performed by men and women in the society. Lakoff (1975) states that due to some cultural considerations, a word like lady is used instead of the word woman in many contexts. This word is treated as a euphemism as well as the euphemistic expression housewife, which describes women's role in English. In fact, Lakoff (1975) indicates that lady was a euphemism for woman, but gentleman is not categorised as a euphemism for man. There is no need to refer to men as gentlemen unlike women who are socially and culturally tabooed. Lakoff (1975, p. 58) states that:

to avoid having to resort to terms like 'Afro-American', we need only to get rid of all expressions like 'nigger'; to banish 'lady' in its euphemistic sense from the vocabulary of English, we need only first to get rid of 'broad' and its relations.

In other words, Lakoff (1975) claims that this will not be accomplished unless people cleanse their minds and cultures from the idea that blacks are degraded and inferior and women are marginal and powerless.

In another study, Wareing (2004, p. 76) discusses sex and gender. He indicates that "sex refers to biological category, which is usually fixed before birth. Gender refers to social category, which is associated with certain behaviour". Wareing (ibid) states that there are specific areas in which both Arab males and females use euphemistic expressions in their conversation. Both males and females tend to take the Politeness Principle into account when they interact with each other; males with females and vice versa. The only difference is that females use it all the time and in all types of conversation in Arabic. Here, it is worth pointing out that the 
current study attempts to support this argument. In addition, it focuses on the use of euphemism in English as a foreign language. It is important to see if females perform better than males with regard to the use of euphemism in another language i.e. English.

In a recent study, Yu-jing (2007) posits that males, apparently, use straightforward and clear strategies to express their opinions and ideas. On the other hand, to preserve their face, women tend to use different indirect methods to convey their ideas. Yu-jing (ibid) concludes that different social values generally affect the gender's use of language. He explains that usually people strive to preserve their face. This may be due to the fact that people seek to be respected by others. This does not mean, however, that gender differences are absent. Specifically, Yu-jing (2007) indicates that males tend to preserve their negative faces, whereas females focus more on their positive faces. Similarly, Xi (2007) explains that there is a strong relation between euphemism and gender. In their daily conversations, women tend to follow the Politeness Principle. However, men often ignore this principle while speaking. Overall, age, gender, social class and educational level, are viewed as the main factors that affect the use of language in general and euphemistic expressions in particular.

It can be observed that several studies worldwide focused on cultural differences in the use of euphemistic expressions by EFL learners. However, little attention has been given to Arab EFL learners' ability to comprehend euphemistic expressions in English. Hence, this study attempts to bridge this gap by answering the following questions:

1) To what extent does Arab EFL learners' gender play a role in their awareness of euphemism in English?

2) Does Arab EFL learners' English proficiency level play a role in their understanding of euphemistic expressions in English?

\section{Methodology}

\subsection{The Sample}

Forty participants, students at Al Ain University of Science and Technology, were involved in the study. Their ages were between 18 and 26; their mean age was 22.The participants were chosen randomly and divided into groups. In particular, they were divided into four groups on the basis of the two variables, namely, gender and English proficiency level. Concerning gender, the participants were divided into two groups: group 1 (20 male learners (ML)) and group 2 (20 female learners (FL)). With respect to their English proficiency level, the same groups (ML and FL) were also divided into two groups; 20 advanced learners (AL) and20 intermediate learners (IL). The classification was based on their IELTS scores: those who got 4 or 4.5 were considered intermediate, whereas those who got 5 or 5.5 were considered advanced. Table 1 below describes the classification of the participants:

Table 1. The classification of the participants

\begin{tabular}{lll}
\hline Number of participants & Gender & English proficiency level \\
\hline 10 & Male & Advanced \\
10 & Male & Intermediate \\
10 & Female & Advanced \\
10 & Female & Intermediate \\
\hline
\end{tabular}

Table 1indicates that the participants were divided into four different groups as follows:

1. $20 \mathrm{ML}$ (Male Learners)

2. $20 \mathrm{FL}$ (Female Learners)

3. $20 \mathrm{AL}$ (Advanced Learners)

4. 20 IL (Intermediate Learners)

We assured the participants that their data will be handled with care and consideration. We informed them that their participation is voluntary and that they can withdraw their consent to participate at any time without any penalty. Finally, we thanked the participants for their willingness to participate in the study.

\subsection{The Test}

It has been indicated that the multiple-choice test is the most common and widely used assessment tool for the measurement of knowledge, ability and complex learning outcomes (Nicol, 2007, p. 54). Hence, we chose this 
test based on our belief that it is one of the best methods to test the ability of the participants to recognise euphemistic expressions in English. The test used in this study included 10 euphemistic expressions (see Appendix A):

Chubby instead of $f a t$

Pass away instead of die

Slim instead of skinny

Unmotivated instead of lazy

On the street instead of homeless

Freedom fighters instead of rebels

Modest instead of poor

Disabled instead of handicapped

Visually challenged instead of blind

Vertically challenged instead of short

It is worth noting that the participants were aware of the meanings of all the above-mentioned words. The choices on the test were designed as follows: one correct answer (euphemistic expression), one wrong answer (the offensive expression),one distracter, and one I don't know option, which was used to limit the probability of choosing the wrong answer and ensure the reliability of the test. The euphemistic expressions were collected from a dictionary of euphemism called: How Not to Say What You Mean (Holder, 2002). To ensure that these euphemistic expressions are used in modern speech, we checked their frequency in the Corpus of Contemporary American English (COCA). Only the most frequent expressions were used in the current study. For example, the frequency of the words slim is 5106 times and modest is 11069 times in the COCA, which is very high. Finally, the contextualized sentences used in the test were adapted from the COCA with some changes to be compatible with the participants' English proficiency level.

\subsection{Research Hypotheses}

The study seeks to confirm the following hypotheses:

Hypothesis 1 (H1): There are statistically significant differences between the answers ofgroup1 (Female Learners FL) and group 2 (Male Learners ML).

Hypothesis 2 (H2): There are statistically significant differences between the answers of advanced learners (AL) and intermediate learners (IL) of English.

\subsection{Statistical Analysis}

The Statistical Package for the Social Sciences (SPSS) was used to calculate the results. The following statistical methods were utilised to analyse the data:

1) Means and standard deviations of the answers were used to analyse the responses of each group regarding the answers in the test.

2) T-tests were conducted to test the two hypotheses and to determine whether there are statistically significant differences between the groups. The t-tests were used to compare; firstly, the results of (ML) and (FL) in order to test the first question i.e. to what extent does Arab EFL learners' gender play a role in their awareness of euphemism. Secondly, the results of (AL) and (IL), in order to test the second question i.e. to what extent does Arab EFL learners' English proficiency level play a role in their understanding of euphemistic expressions.

\section{Results and Discussion}

Testing (H1), table 2 demonstrates that females $(\mathrm{M}=4.9)$ perform better than males $(\mathrm{M}=2.7)$. Hence, there is a statistically significant difference between the ML group and the FM group in terms of using euphemistic expressions; the statistical significance $(0.009)$ is lower than $(0.05)$. 
Table 2. Results of t-test of differences between (FL) and (ML)

\begin{tabular}{lllllll}
\hline Gender & $\mathrm{N}$ & $\mathrm{M}$ & $\mathrm{SD}$ & $\mathrm{t}$ & $\mathrm{df}$ & Sig. \\
\hline Male & 20 & 2.7 & 2.3 & -2.121 & 38 & $0.009^{* *}$ \\
Female & 20 & 4.9 & 2.1 & & & \\
\hline
\end{tabular}

**Significance level $<0.05$.

Table 3 provides a detailed analysis of the results obtained, showing the percentages of correct answers of every item on the test.

Table 3. Percentage of correct answers in terms of gender

\begin{tabular}{llll}
\hline & \multicolumn{2}{l}{ Number of correct answers $\%$} & \\
\cline { 2 - 3 } Vocabulary items & Males & Females & Mean of totalanswers \% \\
\hline chubby & $20 \%$ & $60 \%$ & $40 \%$ \\
pass away & $50 \%$ & $60 \%$ & $55 \%$ \\
unmotivated & $10 \%$ & $40 \%$ & $25 \%$ \\
on the street & $20 \%$ & $30 \%$ & $25 \%$ \\
freedom fighters & $40 \%$ & $30 \%$ & $35 \%$ \\
modest & $20 \%$ & $40 \%$ & $30 \%$ \\
disabled & $40 \%$ & $60 \%$ & $50 \%$ \\
visually challenged & $30 \%$ & $50 \%$ & $40 \%$ \\
vertically challenged & $10 \%$ & $50 \%$ & $30 \%$ \\
slim & $30 \%$ & $70 \%$ & $50 \%$ \\
Mean of total answers $\%$ & $27 \%$ & $49 \%$ & $38 \%$ \\
\hline
\end{tabular}

Three important results can be observed based on table 3. Firstly, Arab EFL learners have little awareness of euphemistic expressions. The total average of both males (27\%) and females (49\%) was below the passing average $(50 \%)$. It is true that females obtained better results than males. However, the total average $(38 \%)$ shows the general lack of understanding of euphemism in English. The lowest percentage scored by the participants was on the expressions unmotivated and vertically challenged (males $=10 \%$ ). This could be due to the fact that the participants are not aware of euphemism as a phenomenon; they did not know that lazy and short are inappropriate to say. Even though they knew the meaning of these euphemistic expressions, they did not choose them on the test.

Secondly, females did better with words, such as slim (70\%), chubby (60\%), pass away (60\%), visually challenged (50\%), vertically challenged (50\%), and modest $(40 \%)$ in comparison with on the street $(30 \%)$ or freedom fighters (30\%). The reason for this could be that females are more interested in physical appearance than males that is, they pay more attention to their speech when it is related to their physical appearance or that of others. For example, since most females do not like to be called fat, they will avoid using that word and use chubby instead. It is may be obvious that most FL may do better with euphemistic expressions in the area of physical appearance. Also, it is worth pointing out that in Arab societies, females are always encouraged to speak very politely in comparison with males. People will criticise females if they speak impolitely, whereas males have more freedom regarding their speech.

In addition, females, as generally known, may not be interested in violence and politics as much as males. Thus, we can see that females got less than the total average of both groups $(35 \%)$ on the expression freedom fighters. In contrast, males' $(40 \%)$ score was better than females $(30 \%)$ on the item freedom fighters; their average was higher than the overall average of both groups $(35 \%)$ on that item. In other words, different areas may have different impact on the extent of awareness concerning the use of euphemistic expressions between females and males.

Thirdly, it can be noticed that both males (50\%) and females (60\%) gave the correct answer with regard to the euphemistic expression pass away. This may be due to cultural factors related to the society where the speakers live. In Arab societies, death is a very serious event in which every single person, within a town or a village, usually attends the funerals of people who pass away to offer condolences, even if the deceased person is not a relative. This helps speakers to be more aware of this expression, especially in the United Arab Emirates (UAE) where there are many residents whose first language is English. Hence, such occasions may motivate speakers to search for the best phrase to use to avoid being corrected by a friend when they use the word to offer 
condolences. Thus, males tend to pay more attention to their negative face i.e. males are more concerned with protecting their self-image compared to females who focus more on their positive face i.e. females are more concerned with being appreciated by others (cf. Yu-jing, 2007).Also, the equivalent of pass away is available and highly frequent in Arabic. For instance, the Arabic verb twaffaa 'he passed away' is the equivalent of the English euphemistic expression pass away.

Testing (H2), whether AL and IL groups perform differently with regard to using euphemistic expressions in English, it seems that English proficiency level plays no role in the use of euphemism. The statistical significance $(0.242)$ is more than $(0.05)$, which means that there is no statistically significant difference between the results of AL group and IL group as shown in table 4.

Table 4. Results of t-test of differences between AL and IL

\begin{tabular}{lllllll}
\hline Level & $\mathrm{N}$ & $\mathrm{M}$ & $\mathrm{SD}$ & $\mathrm{t}$ & $\mathrm{df}$ & Sig. \\
\hline Advanced Learners & 20 & 4.2 & 1.8 & -1.123 & 38 & $0.242^{*}$ \\
Intermediate Learners & 20 & 3.4 & 1.6 & & & \\
\hline
\end{tabular}

*Significance level $>0.05$

Although there is a minor difference between the mean of AL $(M=4.2)$ and the mean of IL $(M=3.4)$, this difference was not enough to differ statistically. AL performed better than IL with only (0.8), which is the difference between the means of the two groups.

Furthermore, the descriptive statistics shown in table5 indicates that IL group obtained similar results to those of $\mathrm{AL}$, especially on words like pass away, chubby, modest and slim.

Table 5. Percentage of correct answers in terms of English proficiency level

\begin{tabular}{llll}
\hline \multirow{2}{*}{ Vocabulary items } & \multicolumn{2}{l}{ Number of correct answers $\%$} & Mean of total answers\% \\
\cline { 2 - 3 } chubby & Advanced & $30 \%$ & $40 \%$ \\
pass away & $50 \%$ & $50 \%$ & $55 \%$ \\
unmotivated & $60 \%$ & $20 \%$ & $25 \%$ \\
on the street & $30 \%$ & $20 \%$ & $25 \%$ \\
freedom fighters & $30 \%$ & $30 \%$ & $35 \%$ \\
modest & $40 \%$ & $30 \%$ & $30 \%$ \\
disabled & $30 \%$ & $50 \%$ & $50 \%$ \\
visually challenged & $50 \%$ & $40 \%$ & $40 \%$ \\
vertically challenged & $40 \%$ & $30 \%$ & $30 \%$ \\
slim & $30 \%$ & $40 \%$ & $50 \%$ \\
Mean of total answers $\%$ & $60 \%$ & $34 \%$ & $38 \%$ \\
\hline
\end{tabular}

With respect to the performance of $\mathrm{AL}$ and IL in relation to the words used, pass away (55\%), slim (50\%) and disabled $(50 \%)$ were the highest percentages. The high percentage of slim may be due to its high frequency in modern speech as shown in the COCA; it occurs 5106 times. Also, it can be argued that both levels i.e. AL and IL exhibited little awareness of euphemistic expressions in English due to language economy factors (Conrad, 1972). As far as the authors are concerned, it seems true that learners tend to stop learning new words in L2 as long as they already have an 'equivalent'. Here, it is important to stress that 'equivalent' means 'having a word which is close to another one in meaning' such as slim and skinny. For Arab EFL learners, both pass away and die almost mean the same. Therefore, they may think that it is not necessary to learn pass away as long as they have die in their lexicon. In addition, it can be argued that the participants in general do not have enough interaction with native speakers of English. Hence, their awareness of euphemistic expressions is low. Finally, with respect to the word disabled, both males and females scored $(50 \%)$ on this item. It seems that this expression is familiar to the participants due to the increasing number of movements that demand the protection of the disabled rights around the world in general and in the UAE in particular.

Looking back at the $\mathrm{H} 2$, the results show that $\mathrm{H} 2$ was not confirmed that is, there is no statistical significant difference between the performance of AL and IL in terms of their awareness of euphemism in English. 


\section{Conclusion}

To sum up, Arab EFL learners have little awareness of euphemism in English. However, enough evidence was provided to support the claim that gender plays a crucial role in the use of euphemism as females performed better than males on the test, especially on the items related to physical appearance. This can be due to the requirements of the Arab society as females should speak more politely than males. Therefore, females show fair awareness of euphemistic expressions related to physical appearance. However, with regard to English proficiency level, both advanced and intermediate learners of English show little awareness of this phenomenon. This could be due to three reasons; (1) Arab EFL learners have not been exposed to this phenomenon at schools; (2) language economy factors in which learners avoid learning new words in L2 as long as they have the alternatives. For instance, one may say that the phrase $X$ is blind is the same as $X$ is virtually challenged; and (3) Arab EFL learners do not have enough interaction with native speakers of English. Thus, educational leaders, curriculum designers and teachers should take serious steps to raise EFL learners' awareness of euphemism in English and its crucial significance in every-day life conversation. More activities should be added to the school curriculum. It seems important for EFL learners to start learning euphemistic expressions in English at earlier stages. Finally, it is also recommended that several studies need to be conducted: (1) to see to what extent do Arab translators transfer the connotations of euphemistic expressions from English to Arabic; and (2) to investigate the areas of euphemism in which females perform better than males and vice versa in L2.

\section{References}

Conrad, C. (1972). Cognitive economy in semantic memory. Journal of Experimental Psychology, 92(2), 149-154. http://dx.doi.org/10.1037/h0032072

Fershtman, C., Gneezy, U., \& Hoffman, M. (2011). Taboos and identity: considering the unthinkable. American Economic Journal: Microeconomics, 139-164. Retrieved from http://rady.ucsd.edu/faculty/directory/gneezy/docs/taboo.pdf

Frajzyngier, Z., \& Jirsa, B. (2006). The Principle of indirect means in language use and language structure. Journal of Pragmatics, 38, 513-542. http://dx.doi.org/10.1016/j.pragma.2005.03.010

Fromkin, V., \& Rodam, R. (1993). An Introduction to Language. New York: Harcourt Brace College Publishers.

Hai-Long, J. (2008). Intercultural study of euphemisms in Chinese and English. Sino-US English Teaching, 5(8), 54-58.

Holder, R. W. (2002). How Not to Say What You Mean A Dictionary of Euphemisms. Oxford: Oxford University Press.

Lakoff, R. (1975). Language and woman's place. Language in Society, 2(1), 45-80. http://dx.doi.org/10.1017/S0047404500000051

McArthur, T. (1992). The Oxford Companion of the English Language. New York: Oxford University Press.

Nicol, D. (2007). E-assessment by design: using multiple-choice tests to good effect. Journal of Further and Higher Education, 31(1), 53-64. http://dx.doi.org/10.1080/03098770601167922

Rawson, H. (1981). A Dictionary of Euphemisms and Other Doubletalk. New York: Crown.

Stien, H. F. (1998). Euphemism, Spin and the Crisis in Organizational Life. Westport, CT: Quorum Books.

Wareing, S. (2004). Language and gender. In Singh, I. \& Peccei, J. (Eds.), Language, Society and Power: An Introduction (pp. 76-92). London: Routledge.

Xi, L. (2007). Gender differences in speech behavior. US-China Foreign Language, 5(3), 17-21.

Yu-jing, H. (2007). Gender language difference: A new interpretation of Face Saving Theory. US-China Foreign Language, 5(1), 5-8.

Zizheng, P. (2005). English Euphemism Teaching. Master thesis, Anhui University. Retrieved from http://www.modilinguistics.com/PAPERS/2005/Pan\%20Zizheng.doc 


\section{Appendix A}

\section{The Test}

Level:

Gender:

Q1: choose the best answer to complete the following sentences.

1. In a clothes shop for women, a girl with her friend was trying on dresses for the school ball:

Her friend: I think the pink dress suits you.

The girl: It is a bit tight though,

Her friend: Oh, Sorry! You are a little bit
a) fat
b) chubby
c) red-head
d) I don't know

2. At the university cashier's office, a student is asking to pay the tuition fees in instalments

The cashier's colleague: why does he want to pay in instalments?

The cashier: he is
a) stupid
b) poor
c) modest
d) I don't know

3. With a very busy schedule, it was good of Prof Kate to find time to come to speak to us on the subject of working with the mentally
a) handicapped
b) sick
c) disabled
d) I don't know

4. Some children at school are them with Braille. , so the administration asked for a couple of volunteers who can help
a) blind
b) funny
c) visually challenged
d) I don't know

5. She wears high heels all the time; she is convinced that she is
a) vertically challenge
b) short
c) blonde
d) I don't know

6. Up to $\$ 500$ million worth of weapons intended for Libyan since the country's uprising began in 2011.
a) rebels
b) freedom fighters
c) displaced
d) I don't know

7. I think Linda should put on some weight; she is so
a) slim
b) skinny
c) polite
d) I don't know

8. A hundred and thirty thousand London homes were destroyed, so the precise number of people who are is now estimated to be around a quarter of a million.
a) homeless
b) on the streets
c) ugly
d) I don't know
9. Many world leaders attended the funeral of Nelson Mandela. He at the age of 95 .
a) passed away
b) died
c) travelled
d) I don't know

10. His parents were very disappointed with him; he has been missing school recently. His teachers said that he sleeps during class sometimes. I think he is
a) lazy
b) unmotivated
c) tall
d) I don't know

\section{Copyrights}

Copyright for this article is retained by the author(s), with first publication rights granted to the journal.

This is an open-access article distributed under the terms and conditions of the Creative Commons Attribution license (http://creativecommons.org/licenses/by/3.0/). 